\title{
Problem Solving In Science Learning - Some Important Considerations of a Teacher
}

\author{
Dr. Rajib Mukhopadhyay \\ Department of Education, St. Xavier's College, Kolkata
}

\begin{abstract}
Problem solving skill is one of the major quality parameters of a person living in the modern society, which is highly technical, scientific, as well as complex. Problem solving, in the context of learning science has been selected as focal theme of the present investigation.

The study has explained importance of a problem to a scientist and a science learner both. In this relation, the philosophical perspective of science has been explained in details. With reference to this, present study has identified the important role of a problem to a scientist which leads to exploration of new scientific knowledge. Relevance of a problem to a science learner has also been explained. Various skills necessary for a learner to solve a problem in science has been discussed. The discussion reveals that problem solving activity helps a learner in constructing new scientific knowledge, and thereby facilitates science learning. The study also has identified the similarity of problem solving activity of a science learner with the way through which a scientist investigates a problem in nature leading to scientific invention. In relation to this, the possibility of strong association between creativity and problem solving activity, in the context of science learning has been discussed also. Discussion is supported by adequate research evidence. Ultimately, the role of a science teacher to encourage problem solving activity emerging creative solutions has also been identified, in view of all these.
\end{abstract}

Keywords: Problem solving, Creativity, Science learning, Role of a science teacher.

\section{Introduction}

Due to advancement of science and technology, modern society is becoming increasingly complex. Multidimensional problems are emerging in it. Society needs a large number of skilled persons who can contribute significantly for its development by providing solutions to those emerging problems. In fact, effective problem solving is not only essential for survival of the society, it is equally important for future prosperity of the society (Khalick \& Lederman, 2000). Students are the future citizens and utilization of their potential might influence progress of the nation favorably. Problem solving skill might enable them to deal with various emerging challenges effectively. Therefore, development of students' problem solving skill is one of the needs of the hour.

But to provide mere routine and ordinary solutions of problems emerging in the contemporary society are inadequate to accelerate rate of progress of the nation. Rather consideration of various different aspects of these multidimensional problems with creative vision leading to wide variety of solutions having novelty and high social relevance are more effective ( Baer \& Kaufman, 2005), in this regard. This is possible only when learners' ability of problem solving and creativity are encouraged simultaneously. In fact, development of the skill of problem solving, in contemporary societal context, should also be associated with fostering their creative vision, which ensures the possibility of emergence of creative solutions of various multidimensional and critical challenges. Investigation of problem solving in the context of learning is drawing gradually increasing attention of researchers (Erdner, 2003), might be in view of this.

Contemporary research and theory on problem solving argue that problem solving skills are domain and context specific, that, problem solving activities are situated, embedded, and therefore dependent on the nature of the context or domain. This is because solving problems within a domain relies on cognitive strategies (strong methods) that are specific to that domain (Mayer, 1992; Smith, 1991; Sternberg \& Frensch, 1991). The same domain specificity is equally applicable in case of investigating creativity, in the context of learning also. Amabile (1987), Baer \&Kaufman (2005) emphasized on the need for specific domain or discipline- based knowledge and skills for fostering creative thinking in relation to learning. Barron (1988), Gardner (1994), Diakidoy \& Constantinou (2001) etc. also have recognized the importance of context (or domain) specific study on creativity and therefore support the view. Morten \& Vanesa (2007) pointed out that each individual subject should emphasize creativity within an agenda reflecting characteristics of each, indicating also the domain specific nature of learning based creativity. This is why domain-specific study of problem solving activity and creativity are gradually becoming more and more important.

Among various disciplines taught in the institution, science particularly seems to have enough scopes to encourage problem solving skills. In fact, problem solving is the essence of scientific investigation (Meador, 
2003). Not only that, science also has immense potential of encouraging and nurturing creativity in its own domain. Its axiomatic nature, scope of applying abstract thinking, inductive approach and analytical reasoning in particular, deductive approach and synthetic reasoning in general in understanding science etc. provides a learner greater opportunity in constructing knowledge actively, encouraging his/her creativity (Mukhopadhyay, 2011). Therefore, it is rational enough to consider science as an appropriate domain within which problem solving (particularly, critical problem solving emerging creative solutions) can be investigated thoroughly.

This is also the area of present study. Questions arise in the mind of the present researcher in this regard are: What is the nature of a scientific investigation? How is a problem meaningful to a scientist? Does it lead to exploration of new knowledge? Has a problem any relevance to a science learner ? Whether solving a problem by a scientist and a science learner resemble any similarity? Present study is an attempt to search for the solutions of these. The study particularly aims at :

i. Identifying the way through which scientists investigate a problem in nature.

ii. Investigating the way through which a science learner solves a problem in science.

iii. Identifying whether investigation of a problem by a scientist and solving a problem in science by a learner resemble any similarity.

iv. Identifying whether there lies any creative component in problem solving activity in science learning.

v. Identifying the role of a science teacher in this regard.

These are discussed step by step as follows.

\section{Investigation Of A Problem In Nature By Scientists}

Science is a specialized body of knowledge; knowledge of several facts, phenomenon, laws, theories and their applications etc. A learner has to acquire this accepting the truth established already, recognizing 'science as a product'. At the same time, science is also 'a process', a way of establishing the truth exploring new areas of scientific knowledge. So truth is the major concern of science and science recognizes truth as a product as well as a process.

According to Karl Popper's 'Philosophy of Science', there is no absolute truth. A person only perceives a relative truth, which is tentative. It is 'falsifyable' (Popper, 1959), as well.

Scientists always search for exploring the underlying truth of the natural world. For doing this, they are guided very much by their perception of relative truth, which they develop on the basis of their background knowledge of scientific principles, concepts and theories. If their perception of truth fails to explain reality of natural world, discrepancy between theory and fact appears resulting in problems. In search of the solutions of those problems, scientists formulate multiple hypotheses and testify them stepwise. Scientific investigation thus begins. This ultimately leads to 'falsification' (Popper, 1959), establishing failure of inappropriate hypotheses. Hypotheses, which are not falsified, are retained and considered as the probable solutions of the problem. These are then verified one by one.

Though, the solutions thus emerge are tentative also and subject to further faisification for realizing the truth of more and more higher degree of probability. Popper called this approach as 'error elimination', which helps scientists realize more and more probable truth. This is why science is dynamic and an ongoing activity and results in newer and newer theories to emerge.

Popper's philosophy explains the growth of individual sciences. But scientific progress, what does it really mean, is bigger altogether than this growth of individual sciences. Science integrates many theories and concepts together into a structured whole, having a distinct organic character (Richards, 1989) and advances over a long period. So individual scientific growths cannot adequately explain the progress of science as a whole, in view of this organic character of science. Kuhn (1962) recognized this feature of scientific growth and proposed a new sociological theory to explain a scientific revolution.

According to Kuhn (1962), it is the paradigm which represents the structured whole of a given science and guides research activities of community. This is because the paradigm represents the totality of the background information, the laws and theories which are taught to the aspiring scientists, as if they were true, and which must be accepted by him if he in turn is to be accepted into the scientific community (Richards, 1989).

In case of emergence of problems in any scientific paradigm, solutions are sought within the existing paradigm (Kuhn, 1962). If existing paradigm fails to provide solution to the problems emerged, anomaly appears resulting a crisis in the existing paradigm. According to Kuhn, new discovery begins with the awareness of anomaly, that is that nature has in some way violated the expectations aroused by the paradigm. Continuous scientific searches go on for removal of the anomaly. As a result, the crisis is resolved ultimately, the anomalous becomes the expected. Thus the existing paradigm is transferred into a newer one with a shift in paradigm, leading to scientific revolution.

Thus 'problem' plays a major role in the advancement of science. In 'error elimination approach' (Popper, 1959), a problem leads to an individual scientific growth; whereas a problem results crisis in the 
existing paradigm of science leading to scientific revolution (Kuhn, 1962). So, a problem has its significant relevance to a scientist. In fact, problem solving is the essence of a scientific invention (Wetzel, 2008) leading to exploration of new and newer knowledge.

\section{Solving A Problem In Science By A Learner}

In the context of learning science, when students are given problems or identify problems by themselves, they investigate the situation and search for the solutions of those following the guidelines of problem based learning. Problem based learning in science typically encourages learners' scientific habits of mind. Hoover (1994) has included eight different dimensions to the operational construct, namely: 'Asking Questions'- based on observations and prior knowledge and experience; 'Constructing Hypotheses' - to guide an investigation; 'Designing and conducting a science investigation'; 'Repeated Trials' - conducting an investigation several times to average the data and determine the legitimacy of the data; 'Accurate Records' keeping accurate data for all observations and investigations; 'Drawing conclusions' - based on the scientific investigation and prior knowledge and experiences; 'Using data' - to develop reasonable explanations of scientific investigations; and 'Realizing'- that different conclusions can be drawn from the same set of data and are still correct.

The construct seems to be similar to different methods and procedures of scientific investigation of a learner- known as 'science process skills' (Aktamis \& Ergin, 2008). These skills are classified into two categories - basic and integrated. The six basic science process skills (grades K-12) are: 'Observing' - using the 5 senses to find out information about objects: an object's characteristics, properties, similarities, and other identification features; 'Classifying' - the process of grouping and ordering objects; 'Measuring' - comparing unknown quantities with known quantities, such as: standard and non-standard units of measure; 'Communicating' - using multimedia, written, graphs, images, or other means to share findings; 'Inferring' forming ideas to explain observations; and 'Predicting' - developing an assumption of the expected outcome.

The five integrated science process skills (grades 5-12) include: 'Formulating a Hypothesis' - making a prediction (educated guess) based on evidence of prior research and investigations; 'Identifying Variables' naming and controlling for the independent, dependent, and control variables in an investigation; 'Operational Description'- develop specific terms to describe what is happening in the investigation based on observable characteristics; 'Experimenting' - carrying out an investigation; and 'Interpreting Data' - analyzing the results of an investigation.

Discussion reveals that problem based learning skills (useful in problem solving in science) and the science process skills (useful for scientific investigation of a learner) resemble similarities. Effective use of problem solving skills in leaning science encourages the spirit of learners' scientific investigation leading to an effective science learning.

Therefore, a problem is important for a science learner. Learners begin to search for solution of the problem within their existing scientific knowledge. If the existing knowledge fails to provide the solution, conflict results in their mind. They make continuous attempt for resolution of the arouse conflict, recognize the gaps in their existing knowledge. This challenges their existing knowledge structure, results a change in it and leads to the construction of a new scientific knowledge resulting in effective science learning. This conceptual framework might throw more intense light to explain clearly how do problem solving activities in science leads to learning science.

\section{Scientific Investigation Of Scientists And Problem Solving Activity Of Learners In} Science

Problem solving activity therefore has its significant relevance to a science learner. It does not only result in solution of a particular problem, it also ensures greater possibility of effective science learning. Discussion also indicates relevance of a problem to a scientist, leading to an exploration of new areas of knowledge in science. This ultimately also rises the relevant question that whether problem solving activity of a learner and scientific investigation of a scientist have any common feature? This is explained as follows.

As per the 'error elimination approach', suggested by poppper, sensitive recognition of problem in nature (in the form of inconsistency or anomaly), is the first essential step of scientific investigation of a scientist. When a learner faces a problem in the context of science learning; he/she initially recognizes the problem also in the similar way- the problem solving activity 'asking question' of a learner (as already referred) refers to this similar step.

The problem solving skill 'constructing hypotheses' of a science learner is close to the step 'formulation of multiple hypotheses' followed by a scientist.

Using the problem solving skills- 'repeated trials', 'accurate records', 'drawing conclusions', etc. learners verify those hypotheses step by step; all these are close to the step 'to testify hypotheses by analytical reasoning or suitable experimentation' followed by a scientist. 
In this way various skills of problem solving are similar to the 'error elimination approach' considered by Popper (1959). Not only this, the discussion also reveals that students' problem solving leads to construction of scientific knowledge which has close resemblance to the phenomenon 'paradigm shift' in scientific knowledge leading to scientific revolution, as explained by Kuhn (1962). Therefore, problem solving of a learner is similar to scientific investigation of scientists, in various respects. Scientists are creative by nature inevitably. Therefore, the similarity of problem solving activity of a learner and scientific investigation of a scientist indicates the possibility of creative components in problem solving activity in the context of science learning also. This is discussed in details as follows.

\section{Creativity And Problem Solving Activity:}

Creative thinking is necessary to search for solutions to all kinds of problems that are encountered in daily life and to make new products (Liang,2003). This seems to be important particularly in leaning science. Aktamis \& Ergin (2008) have identified role of creativity in various scientific processes, particularly in introducing problems, formulating hypotheses and designing experiments. These are also few important problem solving skills, as already discussed.

Various models have been proposed by researchers to explain the nature of a creative process. Osborn (1953) has proposed a seven step model. The steps identified are- orientation (pointing up the problem), preparation (gathering pertinent data), analysis (breaking down the relevant material), ideation (pilling up alternatives by way of ideas), incubation (letting up, to invite illumination), synthesis (putting the pieces together), and evaluation (judging the resulting ideas). Koberg \& Bagnall (1981) proposed a similar model, identifying the steps as- to 'accept the situation (as a challenge)', 'analyze (to discover the world of problem)', 'define (the main issue and goals', 'ideate (to generate options)', 'select (to choose among options)', 'implement (to give physical form to the idea)', and 'evaluate (to review and plan again'. Steps identified by these researchers to explain creative process are also close to the skills of analytical thinking used by a science learner in solving a problem.

The discussion indicates the structured nature of a creative process involving various steps similar to the activity of problem solving in learning science. Not only this, problem solving in science can also encourage creative thinking of a learner. Problem solving activity in science leads to construction of new scientific knowledge of a learner helping him in finding new relationships among the variables, generating wide variety of scientific ideas in relation to a concept and a number of solutions of a particular problem which are novel as well as of high social value, encouraging diversity, and creativity, as well.

In fact, creativity has a supplementary role in problem based learning (Khalick and Lederman, 2000). Saxena (1994) has considered problem solving in science as a process containing creative components in each step. In order to develop a fundamental understanding of a problem in science, individual needs to think creatively (Meador, 2003). The best definition of creativity related to problem solving activity in science learning perhaps is suggested by Torrance (1995). The definition is that, "Creativity is recognizing the gaps in the problem or the information, generating ideas or hypotheses, testing these hypotheses, and transmitting the data" (in Aktamis and Ergin, 2008). In view of this definition, Das (2004) explained that creativity originates from the necessity of eliminating a problem, hypotheses are introduced in order to show how to eliminate this problem, and to test these hypotheses experiments are done leading to the solutions, which thereby eliminates the problem ultimately. These are similar to the steps used in solving problems in science.

As a matter of fact, in the context of learning science, creativity and problem solving are strongly interrelated with one another. Effective encouragement of students' problem solving activity in science class also encourages their creative thinking.

\section{Role OF A SCIENCE TEACHER}

In view of the important role of problem solving in science learning, as referred, the present study is suggesting following roles of a science teacher.

Problem solving activity should be encouraged in a science class. Teacher might not emphasize on the ultimate solution of a problem only. Rather, instruction of a science teacher should be designed such that students may learn various steps of searching the solution and feel an active urge for exploring the solution applying those steps.

Science teacher may adopt the problem solving method of teaching along with heuristic approach. Instead of providing only fact and information, science teaching should encourage students' ability of processing information resulting in construction of their knowledge in science through a meaningful science learning. Enough freedom and autonomy should be provided to the students in a science class, particularly in order to facilitate their original thinking ensuring joy and pleasure in learning science.

Evaluation strategy may also be adopted accordingly. Scope of separate marking scheme for selecting each right step of problem solving leading to the solution should be provided instead of preserving the entire 
marks for finding the ultimate solution only. For evaluating outcome of science learning, problems of multiplechoice type (having only one correct answer) are used frequently in the modern system. This ensures high interscorer reliability of the evaluation system undoubtedly, but is not in favor of assessing students' ability in generating multiple hypotheses of a particular problem. Therefore, judicious combination of problems of multiple-choice type, and also problems of multiple answer type (having more than one correct answers) may be used in science assessment. This inclusion of problems having multiple solutions might encourage students' divergent thinking leading to creativity.

Not only the solution of a well defined scientific problem, students should also be provided the scope to identify inconsistency and anomaly in ill-structured problems. This will encourage their ability in recognizing a problem more effectively, the ability which plays the most important role in solving a problem.

All these activities in a science class will help to develop students' skill of problem solving and also foster their creative thinking. They may provide novel solutions of critical problems and thereby contribute significantly for the progress of the nation, in a long run.

\section{References}

[1] Abd-el Khalick, F. \& Lederman, N.G.(2000).The influence of history of science courses on students views of nature of science. Journal of Research in Science Teaching, 37(10), 1057-1095

[2] Abell, S.K. \& Lederman, N.G.(2007). Handbook of Research on Science Education, Lawrence Erlbaum Asssociates:N.Jercy.

[3] Aktamis, H. \& Ergin, O. (2008). The effect of scientific process skill education on students scientific creativity, scientific attitude and academic achievement, Asia Pacific Forum on Science Learning and Teaching, 9(1), Article - 4.

[4] Amabile, T.M. (1987). The motivation to be creative. In S. G. Isaken (Ed.), Frontiers of Creativity research: Beyond the basics (pp: 223-254) Buffalo, NY: Bearly.

[5] Baer, J. \& Kaufman, J. C. (2005). Whence creativity? Overlapping and dual aspect skills and traits. In J. C. Kaufman \& J. Baer (Eds.), Creativity across domains: Faces of the muse (pp. 313-320).Hillsdale, NJ: Lawrence Erlbaum Associates.

[6] Barron, E. (1988). Putting Creativity to work. In R. J. Sternberg (Ed.). The Nature of creativity: Contemporary Physiological Perspectives (PP - 76-98) N.York: Cambridge University Press.

[7] Dass, P.M. (2004). New science coaches: preperation in the new rules of science education. In J, Weld. (Eds).Game of Science Education, Pearson Education, Inc. Allyn and Bacon : Boston.

[8] Diakidoy, N. \& Constantinou, P. (2001). Creativity in Physics: response fluency and task specificity.Creativity Research Journal,13(3), 401-410.

[9] Erdner, N. (2003), Egitimade yaratici...... gelistirilmesi, [online], Retrieved http://www.kho.edu.tr/Yayinlar/Btym/Bilgibonkasi/Genelkon/114/Nustreterdener.htm.visited on 7/09/2011.

[10] Feldhusen, J.F. (1995). Creativity: A knowledge base, metacognitive skill, and personality factor. Journal of Creativity Behaviour, 29, 255-268.

[11] Frederiksen, N. \& Word, W.C. (1988). Study of Creativity in Scientific Problem Solving. Applied Psychological Measurement, Vol. 2, Issue. 1. West Publishing Co.

[12] Gardner, H. (1994). Creative minds. New York: Basic Books

[13] Greeno, J. (1991). A view of mathematical problem solving in school. In M.U. Smith (ed.), Toward a unified theory of problem solving. (pp. 69-98). Hillsdale, NJ: Lawrence Erlbaum Associates.

[14] Hoover, S.M. (1994). Scientific problem finding in gifted fifth-grade Student, The Process Of Reaching Goals. Buffalo, New York.

[16] Kuhn, T.S. (1962). The Structure of Scientific Revolution. Philosopher's Web Magazine. Retrievd from http//www.des.emory.edu/mfp/kuhn dyn.html visited on 2.8.2010.

[17] Liang, J.C. (2003). Scientific attitude and creative accomplishment in science. Research in Science Education, 33(2)

[18] Mayer, R.E. (1992). Thinking, problem solving, cognition (2nd ed.). New York: Freeman.

[19] Meador, K.S. (2003). Thinking creativity about science - suggestions for primary teachers. Gifted Child Today, 26(1), 25 - 30

[20] Morten, P.K. and Vanessa, K. (2007). Creativity in science education: Perspectives and challenges for developing school science. Retrieved from http://www.redorbit.com/news/science/915320/creativity in science education ..../ visited on February 5, 2012.

[21] Mukhopadhyay, R.(2011). Scientific Creativity-Its relationship with Study Approaches, Aptitude in Physics, and Scientific Attitude, Unpublished Ph.D thesis, University of Calcutta.

[22] Osborn, A. (1953). Applied Imagination. New York: Charles Scribner

[23] Popper, K.R. (1959). The Logic of Scientific Discovery, New York: Basic Books.

[24] Richards, S.(1989). Philosophy and sociology of science, Basil Blackwell.

[25] Saxena, S.P. (1994), Creativity and Science Education. retrieved from http//www.education.nic.in/ed 50 years/q6J/ BJ/ 6JBJ0401.htm, visited January 27, 2011.

[26] Smith, M.U. (1991). A view from biology. In M.U. Smith (ed.), Toward a unified theory of problem solving. Hillsdale, NJ: Lawrence Erlbaum Associates.

[27] Sternberg, R.J.\& Frensch, P.A. (Eds.).(1991). Complex problem solving: Principles and mechanisms. Hillsdale, NJ: Lawrence Erlbaum Associates.

[28] Voss, J.F. (1988). Learning and transfer in subject-matter learning: A problem solving model. International Journal of Educational Research, 11, 607-622.

[29] Wetzel, D.R. (2008). Scientific Method and Problem Based Learning. Retrieved from http//www.suit101.com/...../scientific-methodand-problem-based-learning-a65584. Visited on October 8, 2012. 